Oriani, R.A., et al., Calorimetric measurements of excess power output during the cathodic charging of deuterium into palladium. Fusion Technol., 1990. 18: p. 652.

\title{
CALORIMETRIC MEASUREMENTS OF EXCESS POWER OUTPUT DURING THE CATHODIC CHARGING OF DEUTERIUM INTO PALLADIUM
}

\author{
R. A. ORIANI, JOHN C. NELSON, SUNG-KYU LEE, and J. H. BROADHURST \\ University of Minnesota, Minneapolis, Minnesota 55455
}

\section{COLD FUSION Technical Note}

KEYWORDS: anomalous power, calorimetry, cathodic charging

Received May 14, 1990

Accepted for Publication July 26, 1990

A Seebeck-effect calorimeter was used to establish that generation of energy, in excess of the electrical energy input, can occur during the electrolysis of $\mathrm{D}_{2} \mathrm{O}$. The magnitude of the excess power is measured with respect to the electrolysis of $\mathrm{H}_{2} \mathrm{O}$ as the baseline. The excess power levels of $>60 \mathrm{~W} / \mathrm{cm}^{3}$ palladium and excess energies of $74 \mathrm{~kJ}$ cannot be understood in terms of recombination of $\mathrm{D}_{2}$ and $\mathrm{O}_{2}$ within the calorimeter, other chemical reactions, or a storage-and-relaxation mechanism.

The claim by Fleischmann and Pons ${ }^{1}$ of heat generation over and above the power put into the electrolysis of heavy water, $\mathrm{D}_{2} \mathrm{O}$, and its attribution to nuclear fusion have met with much justified skepticism. Although a few investigators, e.g., Huggins ${ }^{2}$ and Appleby et al., ${ }^{3}$ have also reported observing the unexpected heat production, many other workers have reported ${ }^{4}$ negative results. This disparity and the potential importance of the subject serve as the motivation for this technical note.

The calorimeter used in this work is of the Seebeck-effect type. It has 1961 copper-constantan junctions in series occupying the annular space between the concentric cylindrical metal walls of the calorimeter, which are electrically and thermally insulated from each other. The heat generated in an electrolysis cell at the center of the cylindrical cavity sets up a radial temperature gradient that produces a Seebeck electromotive force (emf) in the thermopile, which is fed to a sensitive strip-chart recorder. In this type of calorimeter, any temperature inhomogeneity within the energy-producing object is of no consequence. The end faces, perpendicular to the axis of the cylinder, do not have thermoelectric junctions. They are made of plastic, double walled to contain a dead air space, and serve for input of electric power and outlet of gases. The calorimeter measures $\sim 81 \mathrm{~cm}$ long with a $25-\mathrm{cm}$ i.d., providing ample space for an electrochemical cell and a long closely fitting spiral tube that serves to extract heat from the evolved gases before they escape from the calorimeter. The electrolysis cell is suspended centrally from the spiral tube, and the gases it produces are passed through a trap to encourage condensation within the calorimeter of water vapor carried by the gases before these are conducted into the spiral tube. The calorimeter is immersed in a thermostatically controlled water bath at $28^{\circ} \mathrm{C}$.

The electrolytic cell used a 1-mm-diam $\times \sim 4$-cm-long palladium wire as a cathode, held axially within a coil of platinum wire as the anode. Connections to the electrodes are made by platinum wires. The electrolyte was either $\mathrm{H}_{2} \mathrm{O}$ or $\mathrm{D}_{2} \mathrm{O}$ into which enough lithium metal was dissolved to produce a $0.1 \mathrm{M}$ solution of LiOH or LiOD. Additional electrolyte was not put in during a calorimetric run so that the duration of a run was generally limited by the consumption of water by dissociation and by vaporization, if any. The isotopic purity of the heavy water used (from the Aldrich Chemical Company) was $99.9 \%$. Electrical energy was furnished from a de power supply usually operated in the constantvoltage mode, and the current and voltage were measured by sensitive instruments. The evolved gases were not measured.

To calibrate the calorimeter, electric current is passed through a coil of nichrome wire set into the electrolysis cell envelope in place of the electrodes. Figure la displays the results of a calibration run as a xerographic copy of the recorder chart of the calorimeter emf versus time. The mean emf, $3.93 \mathrm{mV}$, is constant within the noise band of \pm 0.02 $\mathrm{mV}$ over $11 \mathrm{~h}$ at steady state. Using the calibration and its uncertainty, as described below, this noise band corresponds 
to $\pm 0.04 \mathrm{~W}$. Figure 2 presents the electrical calibration curve in which the abscissa is the product of the current and voltage at the calorimeter input connections and the ordinate is the steady-state Seebeck emf of the thermopile, which requires $\sim 80 \mathrm{~min}$ to be established. We estimate the uncertainty in the overall calibration to be $\pm 0.3 \%$.

The dissociation of $\mathrm{H}_{2} \mathrm{O}$ was measured in separate runs, each with $\sim 220 \mathrm{ml}$ of electrolyte containing $0.1 \mathrm{M} \mathrm{LiOH}$ in a cell in which the vacuum-annealed palladium electrode ( $99.9 \%$ purity from Johnson-Matthey) was surrounded by two concentric glass cylinders that, below the electrolyte level but not above, were perforated by many small holes to permit ionic conductivity between the electrodes. The purpose of this cell configuration was to decrease the mixing of the hydrogen and oxygen gases as much as possible to reduce explosion hazards. The hydrogen was made to flow through the spiral tube, made of glass in this configuration, before leaving the calorimeter through an exit tube. The oxygen was allowed to fill the calorimeter cavity and then to exit from the calorimeter through another exit tube with flow resistance larger than that of the exit tube for the hydrogen. It was discovered later that the difference in flow resistance caused differences in electrolyte level between the cathode and anode compartments so that the gases mixed within the dissociation cell. Figure $1 \mathrm{~b}$ is a xerographic copy of the recorder chart, calorimeter emf versus time, of an $\mathrm{H}_{2} \mathrm{O}$ dissociation run beginning with a reduction of input power to the cell after a previous run, showing the approach to steady state and displaying the stability of the signal during $\sim 12 \mathrm{~h}$ at steady state. The signal varies within about $\pm 0.01 \mathrm{mV}$, which, with the uncertainty in the calibration factor, translates to an uncertainty in the power within $\pm 0.02 \mathrm{~W}$. Figure 2 plots the steady-state emf values of various $\mathrm{H}_{2} \mathrm{O}$ dissociation runs versus $I(V-1.48)$, where $I$ is the current, $V$ is the applied voltage at the calorimeter input leads, and $1.48 \mathrm{~V}$ is the faradaic equivalent of the enthalpy of dissociation of $1 \mathrm{~g} \cdot \mathrm{mol}$ of $\mathrm{H}_{2} \mathrm{O}$. The abscissa is the thermal power that must leave through the walls of the calorimeter at steady state, thereby generating the Seebeck emf, and hence must replace the product $I V$ that is appropriate for the electrical calibration. The dissociation runs with $\mathrm{H}_{2} \mathrm{O}$ require $\sim 3 \mathrm{~h}$ to achieve a steady-state calorimeter signal after which the steadiness and the noise in the signal, as well as in the errors in the measurement of the net input power, are such that the scatter of each data point is smaller than the symbols in Fig. 2. The close congruence of the $\mathrm{H}_{2} \mathrm{O}$ results and the electrical calibration shows, among other things, that recombination of hydrogen and oxygen was negligible despite the gas mixing that occurred within the cell, and that the $\mathrm{H}_{2} \mathrm{O}$ runs can serve as the calibration technique for the calorimeter.

The same cell and calorimeter configuration were employed for the dissociation of $\mathrm{D}_{2} \mathrm{O}$ with $0.1 M \mathrm{LiOD}$, using a new palladium electrode from the same stock as for the $\mathrm{H}_{2} \mathrm{O}$ runs, both having been vacuum annealed together. Figure 2 shows that the three data points in this run lie exactly on the line established by the $\mathrm{H}_{2} \mathrm{O}$ experiments and the electrical calibration. For the $\mathrm{D}_{2} \mathrm{O}$, the abscissa represents $I(V-1.53)$ where $1.53 \mathrm{~V}$ is the faradaic equivalent of the enthalpy of dissociation of $\mathrm{D}_{2} \mathrm{O}$. Note that the highest point of the $\mathrm{D}_{2} \mathrm{O}$ runs, at $16.04 \mathrm{~W}$, corresponds to a current density at the palladium cathode surface of only $0.422 \mathrm{~A} / \mathrm{cm}^{2}$, and that the cell was operated at that input power level for $\sim 31 \mathrm{~h}$. No evidence of anomalous power generation (i.e., no deviation from the $\mathrm{H}_{2} \mathrm{O}$ line) is discernible.

The design of this cell made it impossible to attain desirable larger current densities without undesirably large electrolyte temperature levels. Another cell was therefore built in which the attempt to keep the oxygen and hydrogen separate was abandoned, leading to a considerably lower internal cell resistance. The mixed gases were conducted to a liquid trap, to a copper spiral tube in close contact with the inner wall of the calorimeter, and then out of the calorimeter. 

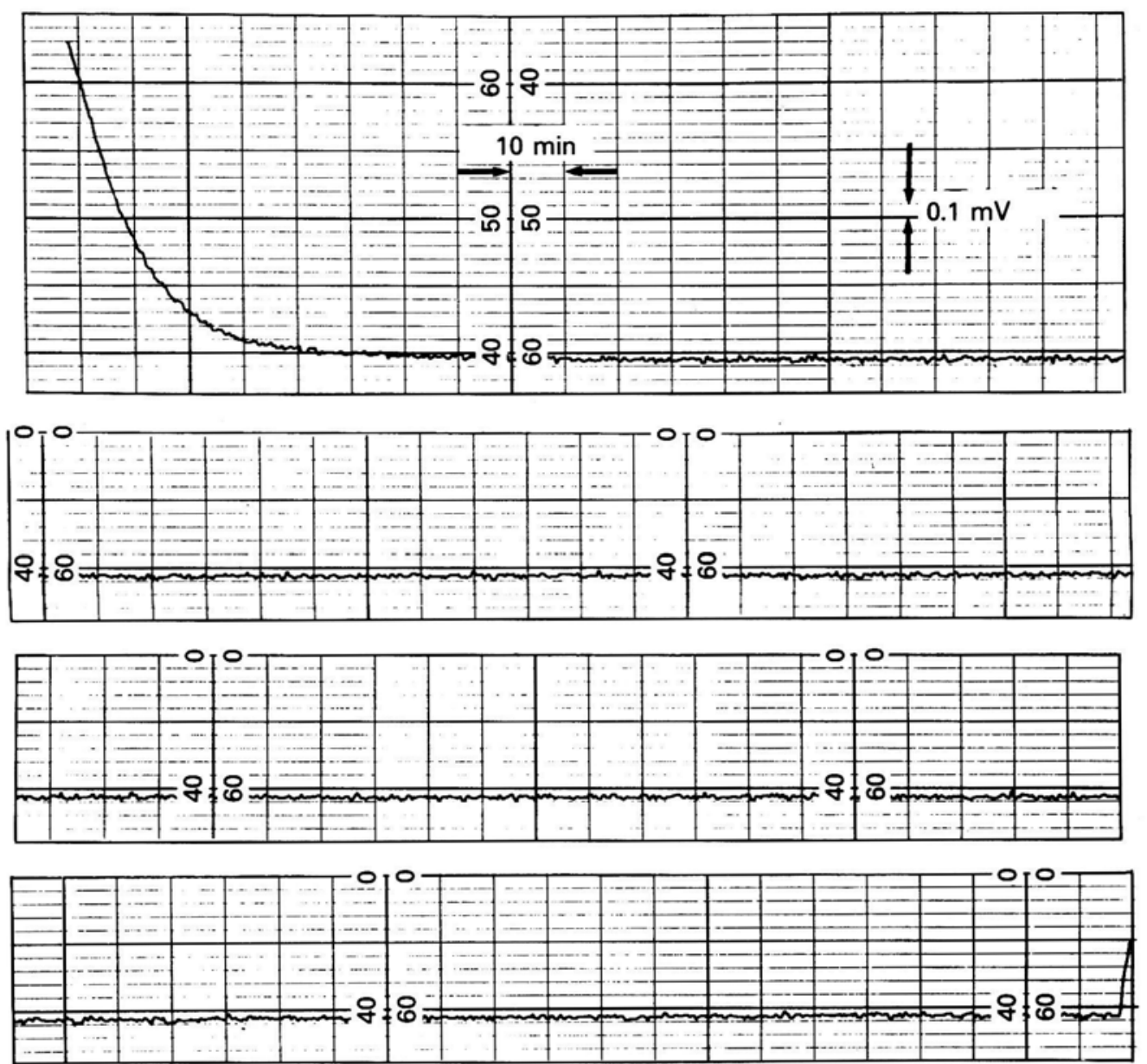

Fig. la. Strip-chart records of an electrical calibration run, showing the degree of steadiness of the calorimeter signal. Time advances from left to right and from the upper to the lower segments. 

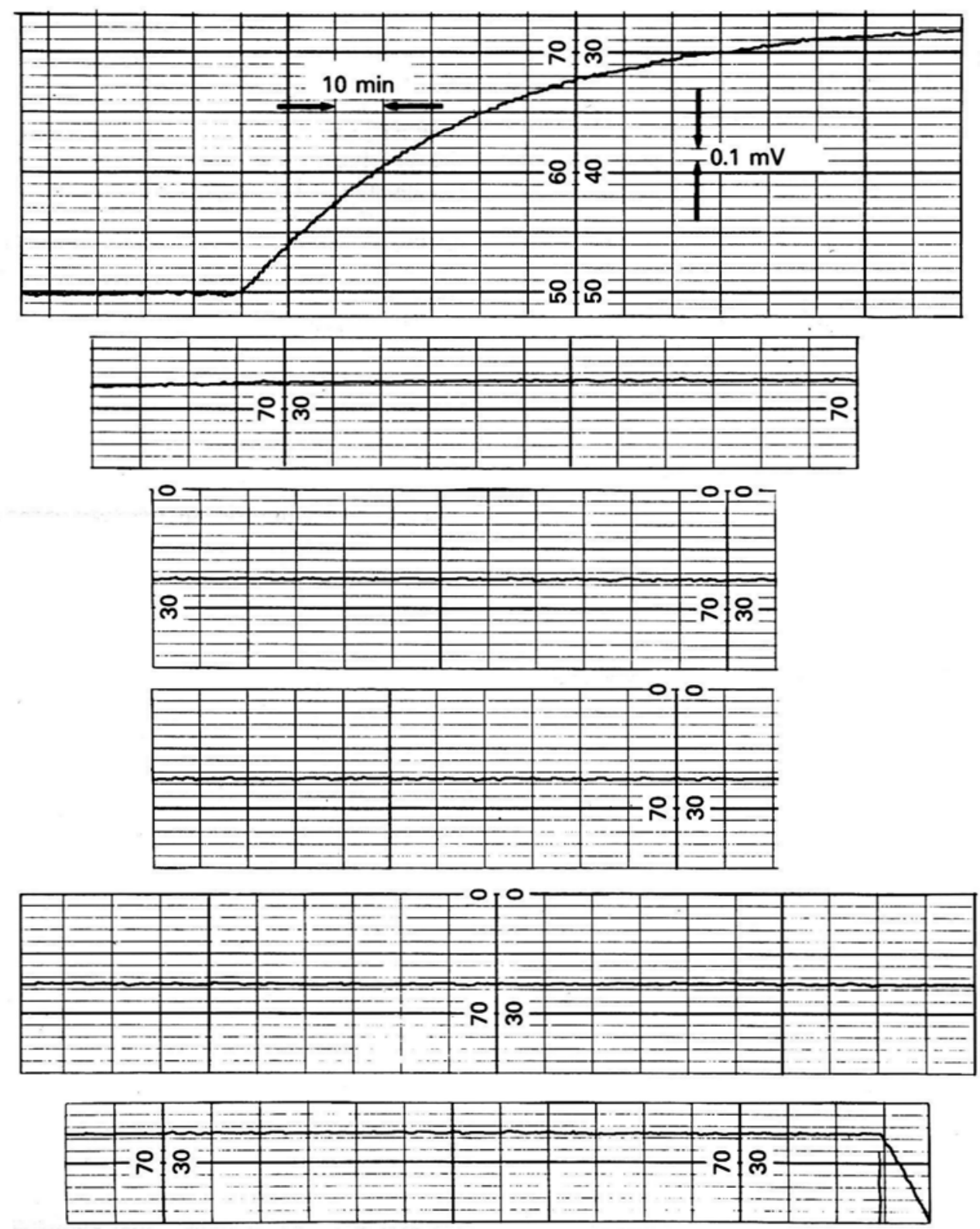

Fig. 1b. Strip-chart records of an $\mathrm{H}_{2} \mathrm{O}$ electrolysis run, showing the degree of steadiness of the calorimeter signal. Time advances from left to right and from the upper to the lower segments

The first run conducted with the low-resistance dissociation cell employed $\mathrm{D}_{2} \mathrm{O}, 0.1 M \mathrm{LiOD}$, and $0.5 \mathrm{ml}$ of concentrated $\mathrm{D}_{2} \mathrm{SO}_{4}$ (from the Aldrich Chemical Company) in $146 \mathrm{ml}$ of electrolyte. The latter was added to decrease the ionic resistance of the electrolyte and to increase the input fugacity of the deuterium, in analogy with what is known to happen with ferrous alloys. ${ }^{5}$ The palladium cathode was $1-\mathrm{mm}$-diam vacuum-annealed wire from the same stock as for earlier experiments. The anode was a spiral of platinum wire, as before, concentric with the cathode. However, a $2.5-\mathrm{cm}$ length of 0.25 -mm-diam palladium wire was spot-welded to the platinum anode. The purpose was to produce asperities of palladium upon the cathode by anodic dissolution from the anode and subsequent cathodic deposition on the cathode. The motivation was the desire to produce very large localized electric fields at the minute palladium protruberances, and therefore large highly localized concentrations of dissolved deuterium within the metallic protruberances, and consequently, very large concentration gradients. This should promote the internal cracking of the palladium, as is known to happen in other metals. ${ }^{6}$ 
We were led to this strategy regarding the possible role of cracks in cold nuclear fusion within metals by the considerations of Mayer et al. ${ }^{7}$

The results of this $\mathrm{D}_{2} \mathrm{O}$ run are shown in Fig. 3; the scatter in each point is smaller than the size of the symbol used to represent it. The first two data points in the experimental sequence lie on the $\mathrm{H}_{2} \mathrm{O}$ line (determined in subsequent experiments with the low-resistance cell). These points represent periods of constant input power of $16 \% / 4$ and $22 \mathrm{~h}$. Then we began to obtain data points anomalously, but definitely above the $\mathrm{H}_{2} \mathrm{O}$ line. As an example, the data point at $11.3 \mathrm{~W}$ showed a constant calorimeter signal of $5.91 \pm 0.05 \mathrm{mV}$ for $>2 \mathrm{~h}$ (after which the input power was decreased); this was preceded by a 4-h rise to steady state. This point corresponds to $1.09 \mathrm{~A} / \mathrm{cm}^{2}$ and to an excess heat flux of $0.70 \pm 0.18 \mathrm{~W}$; i.e., with $\mathrm{H}_{2} \mathrm{O}$, the net input power required to yield the observed calorimeter signal would be $12.0 \mathrm{~W}$. Although the magnitude of the applied current density seems to influence whether anomalous power generation occurs, it is clearly not the only factor. Consider the data point immediately below the above-noted point at $11.3 \mathrm{~W}$. This data point was the last calorimetric steady state measured in this $\mathrm{D}_{2} \mathrm{O}$ run and it lies directly on the $\mathrm{H}_{2} \mathrm{O}$ line. The lowest current density at which excess power was observed in this series was $0.82 \mathrm{~A} / \mathrm{cm}^{2}$, corresponding to the data point at $6.86 \mathrm{~W}$ in Fig. 3.

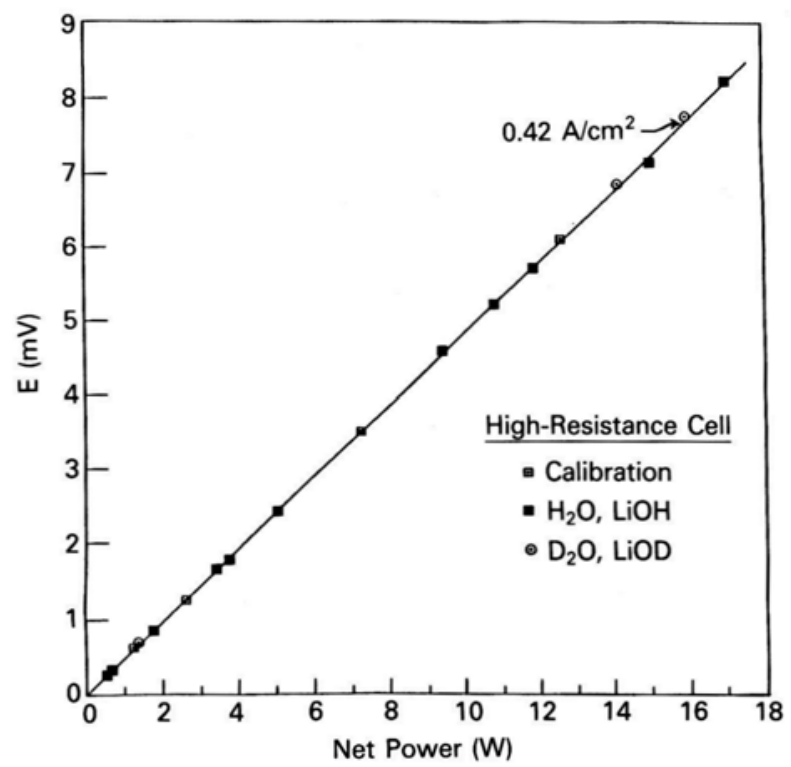

Fig. 2. Calorimeter signal (Seebeck emf) versus net power input for the electrical calibration. 


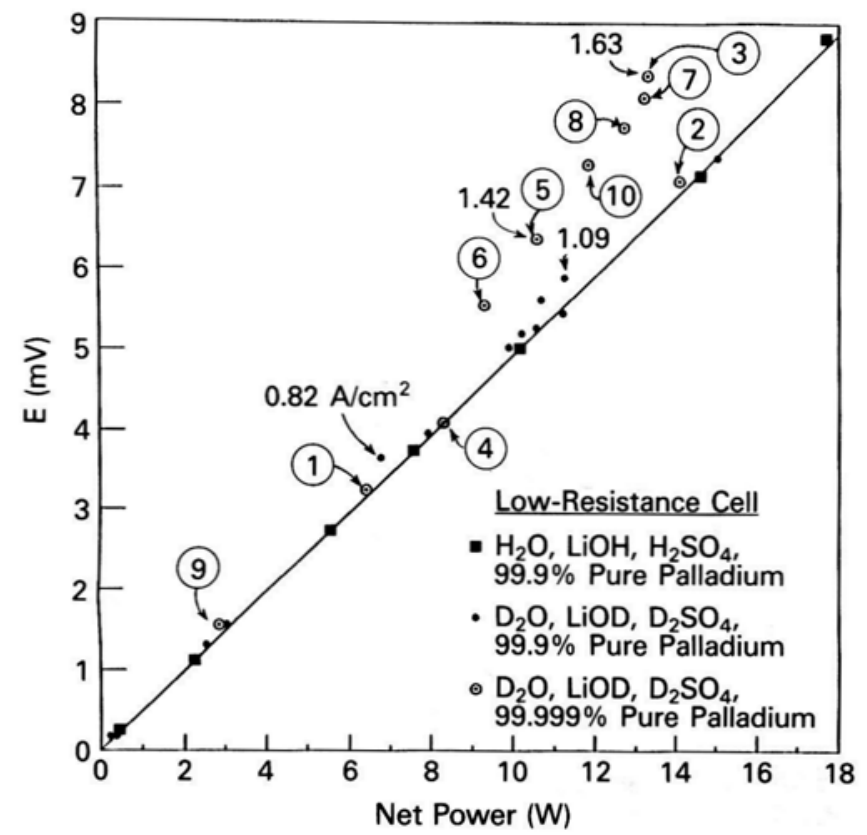

Fig. 3. Calorimeter signal versus net power input for electrolysis in low-resistance cell using acidified electrolytes and palladium wire attached to the platinum anode. Numbers in circles indicate the experimental sequence for the second $\mathrm{D}_{2} \mathrm{O}$ series.

The surprising observation of excess power with the low-resistance cell caused us to question the applicability of the line established with the high-resistance cell for the electrolytic dissociation of $\mathrm{H}_{2} \mathrm{O}$, which coincides with the results of electrical calibration. Therefore, the next experimental series performed with the low-resistance cell was $\mathrm{H}_{2} \mathrm{O}$ dissociation using $0.1 \mathrm{M} \mathrm{LiOH}$ plus $0.5 \mathrm{ml}$ concentrated $\mathrm{H}_{2} \mathrm{SO}_{4}$, a short length of palladium wire spot-welded to the platinum anode, and another palladium wire, of the same provenance as the others, as the cathode. The results of these experiments appear in Fig. 3. A comparison of this $\mathrm{H}_{2} \mathrm{O}$ line with that in Fig. 2 shows that both lines begin exactly at the origin with the line in Fig. 3 having a higher slope, such that at $14 \mathrm{~W}$ the calorimeter signal is nearly $0.2 \mathrm{mV}$ higher. We believe that this small difference arises from the extraction of heat by the copper spiral in the second experimental configuration rather than by the glass spiral.

Another $\mathrm{D}_{2} \mathrm{O}$ dissociation run was performed with the low-resistance cell after the series with $\mathrm{H}_{2} \mathrm{O}$. The new electrolyte was again $0.1 \mathrm{M}$ LiOD plus $0.5 \mathrm{ml}$ of concentrated $\mathrm{D}_{2} \mathrm{SO}_{4}$ in $140 \mathrm{ml}$ of electrolyte, and palladium wire was affixed to the platinum anode. In this run, the cathode was from different stock. It was 1-mm-diam $\times 4.4$-cm-long 99.999\% pure palladium wire and was used without any pre-treatment except cleaning. The results are shown in Fig. 3. The initial point at $6.47 \mathrm{~W}$ represents a steady state lasting $>16 \mathrm{~h}$ and it lies on the $\mathrm{H}_{2} \mathrm{O}$ line established with the lowresistance cell. After this, the input power was increased to $14.16 \mathrm{~W}$ (at $11.298 \mathrm{~V}$ ). As the steady state was being approached, it was noted that the current had exceeded the capacity ( 2 A) of the ammeter used; as the cell temperature increased, the cell resistance decreased so that the current increased at constant applied voltage. The voltage was therefore decreased, and a higher range ammeter was substituted. The point labeled 2 in Fig. 3 represents the calorimeter signal at $1.988 \mathrm{~A}$ and before a steady state had been reached, as indicated in Fig. 4. Point 2 is above the $\mathrm{H}_{2} \mathrm{O}$ line and shows that excess power began generating at some time during the approach to steady state, which takes $\sim 3 \mathrm{~h}$ with the low-resistance cell. At steady state, the calorimeter signal would be above point 2 for that input power of $14.16 \mathrm{~W}$.

Figure 4 displays the interesting phenomenon that the reduction of the input power produced a sudden reversal of the incipient expected lowering of the calorimeter signal. The power output continued to increase at the reduced input of $13.37 \mathrm{~W}(10.491 \mathrm{~V})$ and reached a quasi-steady state $\sim 1 \frac{1}{2} \mathrm{~h}$ later. Point 3 represents an anomalous (excess) power generation of $\sim 3.6 \mathrm{~W}$. To put this in perspective, we note that the power that would be generated by the complete recombination of $\mathrm{D}_{2}$ and $\mathrm{O}_{2}$ within the calorimeter would be $1.53 \mathrm{I}$, which at the measured current equals $3.41 \mathrm{~W}$. Reduction of input power yielded point 4 on the $\mathrm{H}_{2} \mathrm{O}$ line despite the current density of $1.06 \mathrm{~A} / \mathrm{cm}^{2}$. This was followed by several anomalously high points, after which the input power was reduced to $2.903 \mathrm{~W}$, yielding point 9 , which is above the $\mathrm{H}_{2} \mathrm{O}$ line even though the current density is only $0.63 \mathrm{~A} / \mathrm{cm}^{2}$. At this stage of the investigation, it is not 
possible to assert that there exists a threshold current density below which excess power generation does not occur; apparently, the phenomenon is somehow a function of the preceding states.

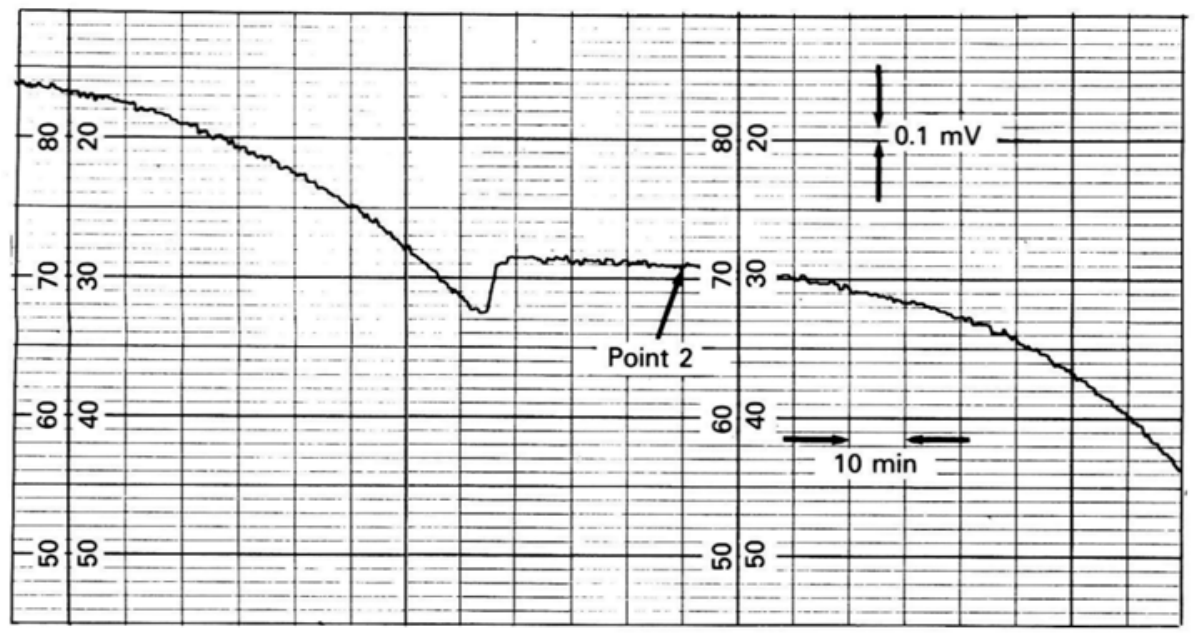

Fig. 4. Section of strip-chart record for the second $\mathrm{D}_{2} \mathrm{O}$ run of Fig. 3, showing the anomalous rise of the calorimeter signal a short time after reduction of input power.

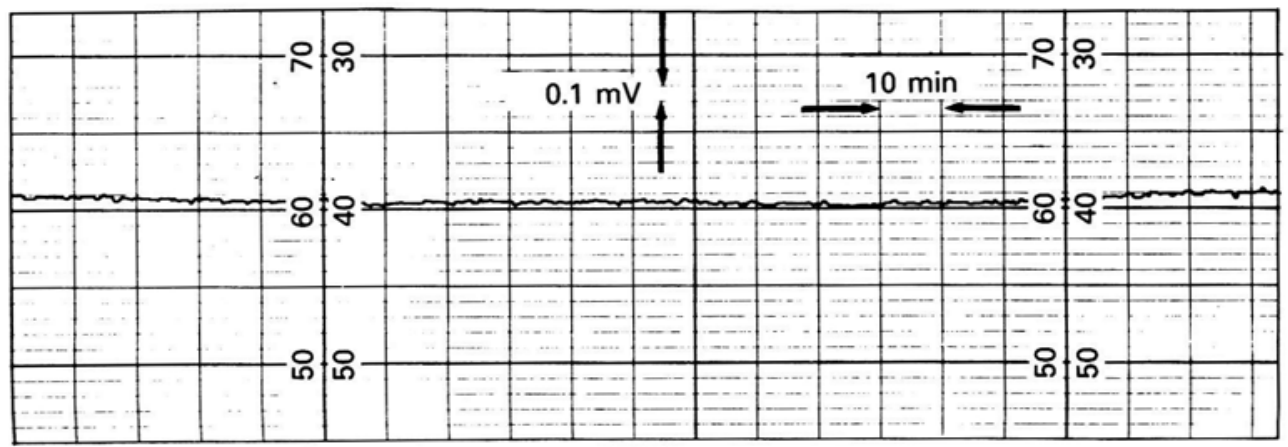

Fig. 5. Section of strip-chart record showing the "waviness" that was often found to accompany excess power production.

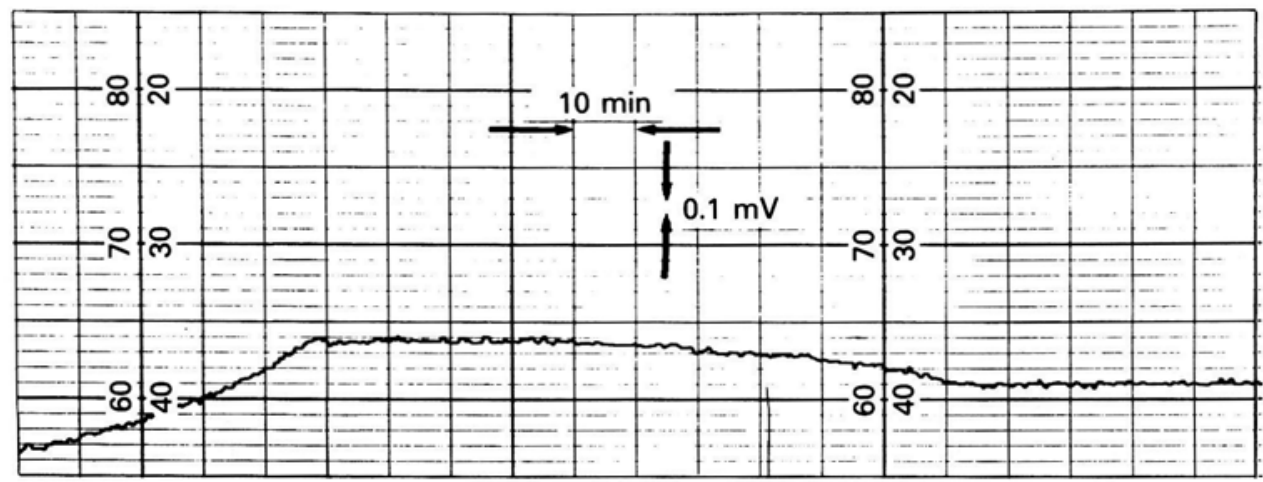

Fig. 6. Section of strip-chart record showing rise of calorimeter signal after a long quasi-steady state, all at constant input power. Time advances from right to left. 
TABLE I

Characteristics of the Second $\mathrm{D}_{2} \mathrm{O}$ Experiment in the Low-Resistance Cell

\begin{tabular}{|c|c|c|c|c|c|c|c|c|c|}
\hline \multirow[b]{2}{*}{ Episode } & \multicolumn{2}{|c|}{ Input Watts } & \multirow{2}{*}{$\begin{array}{c}\text { Duration } \\
\text { (min) }\end{array}$} & \multirow{2}{*}{$\begin{array}{c}E^{\mathrm{a}} \\
(\mathrm{mV})\end{array}$} & \multirow{2}{*}{$\begin{array}{c}E_{0}{ }^{\mathrm{b}} \\
(\mathrm{mV})\end{array}$} & \multicolumn{2}{|c|}{ Input Energy } & \multicolumn{2}{|c|}{ Excess Quantities } \\
\hline & Net & 1.531 & & & & $($ Net kJ) & $($ Total kJ) & (W) & $(\mathrm{kJ})$ \\
\hline 1 & 6.465 & 1.957 & $985^{\mathrm{c}}$ & $3.25^{\mathrm{d}}$ & 3.25 & 382.1 & 497.7 & 0 & 0 \\
\hline 2 & 14.16 & 3.04 & $156^{\mathrm{c}}$ & $7.15^{\mathrm{e}}$ & 6.95 & 132.5 & 160.0 & $0.4 \pm 0.1$ & $-\cdots$ \\
\hline \multirow[t]{2}{*}{3} & 13.37 & 3.41 & $90^{\mathrm{e}}$ & $7.8^{\mathrm{f}}$ & 6.58 & 72.2 & 90.6 & $2.5 \pm 0.2$ & 13.5 \\
\hline & 13.37 & 3.41 & $150^{\mathrm{d}}$ & $8.35^{\mathrm{d}}$ & 6.58 & 120.3 & 151.0 & $3.6 \pm 0.2$ & 32.4 \\
\hline 4 & 8.33 & 2.24 & $320^{c}$ & $4.09^{\mathrm{d}}$ & 4.09 & 159.8 & 202.8 & 0 & 0 \\
\hline \multirow[t]{4}{*}{5} & 10.68 & 2.98 & $30^{\mathrm{e}}$ & - & 5.23 & 19.2 & 24.6 & $-\cdots$ & $\cdots-1$ \\
\hline & 10.68 & 2.98 & $120^{g}$ & $5.8^{\mathrm{f}}$ & 5.23 & 76.9 & 98.4 & $1.16 \pm 0.2$ & 8.4 \\
\hline & 10.68 & 2.98 & 560 & $6.1^{\mathrm{d}}$ & 5.23 & 358.8 & 459.0 & $1.78 \pm 0.2$ & 59.8 \\
\hline & 10.68 & 2.98 & 103 & $6.35^{\mathrm{f}}$ & 5.23 & 66.0 & 84.4 & $2.29 \pm 0.2$ & 14.1 \\
\hline \multirow[t]{2}{*}{6} & 9.36 & 2.80 & $77^{\mathrm{h}}$ & & 4.60 & 43.2 & 56.2 & & \\
\hline & 9.36 & 2.80 & $70^{\mathrm{d}}$ & $5.56^{\mathrm{d}}$ & 4.60 & 39.3 & 51.1 & $1.96 \pm 0.1$ & 8.2 \\
\hline \multirow[t]{3}{*}{7} & 13.27 & 3.44 & $17^{\mathrm{e}}$ & & 6.52 & 13.5 & 17.0 & & - \\
\hline & 13.27 & 3.44 & $63^{g}$ & $7.5^{\mathrm{f}}$ & 6.52 & 50.2 & 63.2 & $2.00 \pm 0.2$ & 7.6 \\
\hline & 13.27 & 3.44 & $68^{\mathrm{d}}$ & 8.1 & 6.52 & 54.1 & 68.2 & $3.23 \pm 0.2$ & 13.2 \\
\hline \multirow[t]{2}{*}{8} & 12.76 & 3.38 & $42^{\mathrm{h}}$ & -- & 6.28 & 32.2 & 40.7 & --1 & $\ldots$ \\
\hline & 12.76 & 3.38 & $33^{\mathrm{d}}$ & $7.78^{d}$ & 6.28 & 25.3 & 32.0 & $3.07 \pm 0.1$ & 6.1 \\
\hline \multirow[t]{2}{*}{9} & 2.903 & 1.33 & $167^{\mathrm{h}}$ & $-\ldots$ & 1.34 & 29.1 & 42.4 & & \\
\hline & 2.903 & 1.33 & $770^{d}$ & $1.56^{\mathrm{d}}$ & 1.34 & 134.1 & 195.6 & $0.45 \pm 0.2$ & 21 \\
\hline \multirow[t]{2}{*}{10} & 11.91 & 3.23 & $44^{\mathrm{e}}$ & - & 5.85 & 31.4 & 40.0 & &.- \\
\hline & 11.91 & 3.23 & $109^{8}$ & $7.0^{\mathrm{f}}$ & 5.85 & 77.9 & 99.0 & $2.4 \pm 0.2$ & 15.4 \\
\hline
\end{tabular}

${ }^{\mathrm{a}} E=$ observed calorimeter signal.

${ }^{\mathrm{b}} E_{0}=$ calorimeter emf of the calibration curve $\left(\mathrm{H}_{2} \mathrm{O}\right.$ dissociation line $)$ at same net power input.

${ }^{\mathrm{c}}$ Total over the entire episode.

${ }^{\mathrm{d}}$ Steady state.

${ }^{\mathrm{e}}$ Rising signal portion of the episode.

${ }^{\mathrm{f}}$ Average over the indicated duration.

${ }^{\mathrm{g}}$ Rising signal portion when $E>E_{0}$.

${ }^{\mathrm{h}}$ Decreasing signal portion of the episode.

Table I lists the raw data and calculated quantities for this $\mathrm{D}_{2} \mathrm{O}$ run. The values of excess power were calculated by subtracting from the observed millivolt signal the amount $E^{0}$ corresponding to the $\mathrm{H}_{2} \mathrm{O}$ line at the same power input, and multiplying the difference by the slope of the $\mathrm{H}_{2} \mathrm{O}$ line: $2.03 \mathrm{~W} / \mathrm{mV} \pm 0.3 \%$. An interesting characteristic that is often, but not always, observed when there is excess power generation is that the calorimeter signal shows an overall waviness of $\sim 0.05-\mathrm{mV}$ amplitude and a wavelength of several hours; Fig. 5 shows an example. This is in strong contrast with the behavior with $\mathrm{H}_{2} \mathrm{O}$ for which the signal is contained within a band of $<0.01 \mathrm{mV}$ (Fig. Ib), and it may be caused by sporadic generation of excess power smoothed out by the large relaxation time of the calorimeter. An egregious example of the variability of the signal during anomalous power generation is shown in Fig. 6, which is a record of the signal-time chart a few hours after the record of Fig. 5. We see in Fig. 6 that at constant input power during which the calorimeter signal had been slowly varying about a mean value of $6.1 \mathrm{mV}$, as described for Fig. 5 , for $\sim 560 \mathrm{~min}$, the Seebeck emf rose to $6.38 \mathrm{mV}$ within $30 \mathrm{~min}$, producing point 5 of Fig. 3. Note that $6.1 \mathrm{mV}$ also represents an anomalous power generation of $\sim 1.8 \mathrm{~W}$. Integrating this excess power over $560 \mathrm{~min}$ and the excess of $\sim 2.3 \mathrm{~W}$ over 103 min gives 
an excess energy of $73.9 \mathrm{~kJ}$ for the episode ending with point 5. Integration of the excess power of all of the episodes of the second $\mathrm{D}_{2} \mathrm{O}$ run with the low-resistance cell yields $\sim 200 \mathrm{~kJ}$ for the total excess energy generated. The excess power output represented by point 5, using units employed by Fleischmann and Pons' is $67 \mathrm{~W} / \mathrm{cm}^{3}$ palladium; point 3 represents $106 \mathrm{~W} / \mathrm{cm}^{3}$ palladium. These numbers are considerably larger than those reported by Fleischmann and Pons ${ }^{1}$ and by Appleby et al. ${ }^{3}$

To examine possible chemical reactions that may be responsible for such magnitudes of energy generation, assume first the exothermic formation of a palladium deuteride that (surprisingly) does not have a corresponding palladium hydride. Assuming that the hypothetical $\mathrm{PdD}_{2}$ has a $\Delta H$ of formation of $-200 \mathrm{~kJ} / \mathrm{mol}$, one calculates that at $1 \mathrm{~A}$ the excess power would be $1.04 \mathrm{~W}$ if all the $\mathrm{D}_{2} \mathrm{O}$ reacted to form hydride. Since our work and that of many others (e.g., Ref. 3) demonstrate that essentially all the $\mathrm{D}_{2}$ leaves the cell at steady state, the calculated excess power from this source decreases by a factor of at least 50 . Furthermore, should such a hypothetical deuteride be formed at high current densities at which a high activity of dissolved deuterium is generated, at low current densities and correspondingly low activities the $\mathrm{PdD}_{2}$ would decompose endothermically and thereby produce abnormally low calorimetric signals (i.e., below the $\mathrm{H}_{2} \mathrm{O}$ line). This is never observed. One can similarly examine the possible exothermic formation of a lithium deuteride for which the corresponding hydride does not form under parallel conditions. Assuming $-200 \mathrm{~kJ} / \mathrm{mol} \mathrm{LiD}$ for the enthalpy of formation, and knowing that our cells had an initial lithium ion content of $0.0104 \mathrm{~mol}$, the maximum possible excess energy would be only $2.8 \mathrm{~kJ}$, not the $73.9 \mathrm{~kJ}$ of excess energy that we observed in the episode leading to point 5 . It is similarly most difficult to conceive of any chemical reactions involving impurities in the metals or in the electrolyte to be responsible for the magnitudes of excess energies in our experiments. Finally, we note that the possibility that the anomalous power is the result of the storage in the system of some energy (such as mechanical strain energy or the formation of an unstable endothermic compound) followed by its subsequent relaxation can be refuted not only by the large magnitudes of excess energies observed here, but also by the realization that during the time of the alleged storage of energy, the calorimeter signal would necessarily fall below the $\mathrm{H}_{2} \mathrm{O}$ line for the corresponding input power. This was never observed.

If nuclear fusion is responsible for the observed excess power, it may be considered that one or more of the following reactions is taking place:

1. $\quad d+d \rightarrow{ }^{3} \mathrm{He}+n+3.269 \mathrm{MeV}(n$ escape energy $=2.452 \mathrm{MeV})$

2. $\quad d+d \rightarrow{ }^{4} \mathrm{He}+\gamma+21.422 \mathrm{MeV}(\gamma$ escape energy $=21.176 \mathrm{MeV})$

3. $\quad d+d \rightarrow \mathrm{T}+p+4.032 \mathrm{MeV}$

4. $\quad{ }^{6} \mathrm{Li}+d \rightarrow{ }^{8} \mathrm{Be} \rightarrow{ }^{4} \mathrm{He}+{ }^{4} \mathrm{He}+23.374 \mathrm{MeV}$

Reactions 1 and 2 produce penetrating radiations with the indicated energies, which would escape from the calorimeter and not contribute to the heat generation. Only the difference between the reaction energy and the escape energy would generate heat. To generate excess power of $1.0 \mathrm{~W}$ by reaction 1 , it would have to produce $7.6 \times 10^{12} \mathrm{n} / \mathrm{s}$. At $1 \mathrm{~m}$ from the calorimeter, the flux would be $\sim 6 \times 10^{7} \mathrm{~cm}^{-2} \cdot \mathrm{s}^{-1}$, which would correspond to a dose rate of $-7.95 \mathrm{rad} \cdot \mathrm{s}^{-1}$, assuming absorption in water and an absorption cross section of $1 \mathrm{~b}$. However, during periods of production of excess power, the calorimeter was monitored by means of a Ludlum neutron monitor, and no neutron signal was observed.

Although a detector specifically designed for gamma rays was not used, radiation of energy corresponding to reaction 2 would interact with the $\mathrm{BF}_{3}$ gas of the detecting element of the neutron monitor to produce a false indication of the presence of a neutron flux. A signal consistent with the gamma flux by reaction 2 was not observed.

Reaction 3 would be demonstrated by finding tritium within the palladium cathode and in the electrolyte after the generation of excess energy. To account by reaction 3 for the excess energy of $\sim 200 \mathrm{~kJ}$ observed during the second successful $\mathrm{D}_{2} \mathrm{O}$ run (Table I), $\sim 3 \times 10^{7}$ tritons should have been produced. The sample from this run was heated to $\sim 1000^{\circ} \mathrm{C}$ for $5 \mathrm{~min}$ and the evolved gas (deuterium plus putative tritium) was catalytically converted to the corresponding oxides. These were diluted with $1.5 \mathrm{ml} \mathrm{H} 2 \mathrm{O}$ and $1 \mathrm{ml}$ of the mixture was added to Ecolite Plus scintillator cocktail from the ICM Corporation and assayed with a well-type (Beckman) scintillator counter. The observed count rate was 24.1 count/min, and the background count was 24.7. Similar negative results were obtained for the deuterium gas evolved during cathodic charging and collected outside the calorimeter. The electrolyte used in this run was not investigated for tritium. The electrolyte used in the first $\mathrm{D}_{2} \mathrm{O}$ run that exhibited excess power generation was analyzed for tritium. The result gave $81 \mathrm{count} / \mathrm{min}$ after the run and $61 \mathrm{count} / \mathrm{min}$ for an unused batch of electrolyte serving as a blank; this result is not considered significant. Negative results were also obtained with the deuterium extracted from the palladium cathode used in the first successful $\mathrm{D}_{2} \mathrm{O}$ run. 
Reaction 4 produces neither penetrating radiation nor radioactive daughter nuclei. After the production of $\sim 200$ $\mathrm{kJ}$ of excess energy hypothetically by reaction $4,5.3 \times 10^{16}$ helium atoms should appear, presumably in the palladium. This is considerably above the natural background for helium in metals $\left[10^{11}\right.$ to $10^{12}$ atom/g (Ref. 8) $]$ and should be easily measurable. However, our means of extraction of the deuterium from the palladium precluded analysis for helium.

Since no nuclear manifestations were observed in this work, we do not assert that the excess power and energy that we have measured is the result of nuclear fusion. We intend to continue this investigation, specifically by incorporating an X-ray detector within the calorimeter, since both reactions 3 and 4 produce charged particles that would recoil in the palladium lattice with sufficient energy to generate the characteristic palladium $\mathrm{X}$ rays at reasonable intensities.

\section{ACKNOWLEDGMENTS}

We are grateful to Dr. Rolf Engel, pediatrician, for making his calorimeter available to us. Dr. O. J. Murphy of Texas A\&M University graciously granted our request for the sample of $99.999 \%$ pure palladium wire used in the second $\mathrm{D}_{2} \mathrm{O}$ run with the low-resistance cell. The help of Shun-Ming Huang and David Dean with some experimental details is gratefully acknowledged.

This work was supported by a special grant from the University of Minnesota.

\section{REFERENCES}

1. M. FLEISCHMANN and S. PONS, "Electrochemically Induced Nuclear Fusion of Deuterium,"/. Electroanal. Chem., 261, 301 (1989).

2. R. A. HUGGINS, "Comparison of Thermal Measurements on Two Fast Mixed-Conductor Systems: Deuterium and Hydrogen in Palladium," Electrochemical Society Mtg., Special Session Cold Fusion, Hollywood, Florida, October $19,1989$.

3. A. J. APPLEBY, S. SRINIVASAN, Y. J. KIM, O. J. MURPHY, and C. R. MARTIN, "Evidence for Excess Heat Generation Rates During Electrolysis of $\mathrm{D}_{2} \mathrm{O}$ in LiOD Using a Palladium Cathode-A Microcalorimetric Study," Proc. Workshop Cold Fusion Phenomena, Santa Fe, New Mexico, May 22-25, 1989.

4. Proc. Workshop on Cold Fusion Phenomena, Santa Fe, New Mexico, May 22-25, 1989.

5. R. A. ORIANI, "Hydrogen Embrittlement of Steels," Ann. Rev. Mater. Sci., 8, 327 (1978).

6. M. E. ARMACANQUI and R. A.ORIANI, "Lattice Expansion and Contraction in Sputtered Metal Films Due to Hydrogen Charging," Mater. Sci. Eng., 92, 127 (1987).

7. F. J. MAYER, J. S. KING, and J. R. REITZ, "Nuclear Fusion from Crack-Generated Particle Acceleration," Proc. Workshop Cold Fusion Phenomena, Santa Fe, New Mexico, May 22-25, 1989.

8. A. O. C. NIER, University of Minnesota, Personal Communication (Sep. 1989). 